\title{
Triptolide-induced cell cycle arrest and apoptosis in human renal cell carcinoma cells
}

\author{
JINGJIE LI*, WENBO ZHU*, TIANDONG LENG* ${ }^{*}$, MINFENG SHU, YIJUN HUANG, \\ DONG XU, PENGXIN QIU, XINGWEN SU and GUANGMEI YAN
}

\author{
Department of Pharmacology, Zhong-shan School of Medicine, Sun Yat-Sen University, Guangzhou, P.R. China
}

Received October 29, 2010; Accepted December 3, 2010

DOI: $10.3892 /$ or.2011.1158

\begin{abstract}
Renal cell carcinoma (RCC) is the most frequent type of renal-originated malignancy. Although nephrectomy is successfully used to save the lives of patients with localized RCC, treatment of advanced and other refractory RCCs is poor and still inadequate. Here, we show that triptolide, a small molecule and a well-known anti-inflammatory and antiimmunity agent used in the clinic, is capable of inducing cell apoptosis via the mitochondrial pathway in the 786-0 RCC cell line. This induction occurred in concert with reduced expression of genes related to the stabilization of mitochondria such as $\mathrm{Bcl}-2$ and $\mathrm{Bcl}-\mathrm{X}_{\mathrm{L}}$. Cell cycle analysis showed that exposure to triptolide decreased the proportion of cells in the G0/G1 and $\mathrm{G} 2 / \mathrm{M}$ phases, and increased the proportion of cells in the $\mathrm{S}$ phase. Cell accumulation in the $\mathrm{S}$ phase can be attributed to reduced expression of cell cycle checkpoint regulators such as cyclin A, cyclin B, CDK1, CDK2 and retinoblastoma proteins $(\mathrm{Rb})$. These results raise the possibility that triptolide-induced apoptosis is mediated by cell cycle arrest. Similarly, in another human RCC cell line, OS-RC-2, triptolide-induced apoptosis and cell accumulation in $\mathrm{S}$ phase were also observed. Therefore, triptolide emerges as a stimulator of apoptosis by influencing coordinate regulation of proliferation and apoptosis, and may be applicable to the treatment of human renal cell carcinoma.
\end{abstract}

\section{Introduction}

Renal cell carcinoma (RCC) derived from renal tubular cells is the most common malignant cancer affecting the kidney, accounting for $90-95 \%$ of renal tumors (1). Despite high effectiveness of nephrectomy in the management of localized RCC, most patients are diagnosed with advanced RCC, which often has distant metastasis and is associated with an estimated

Correspondence to: Dr Guangmei Yan, Department of pharmacology, Zhong-shan School of Medicine, Sun Yat-Sen University, 74 Zhongshan Road II, Guangzhou 510080, P.R. China

E-mail:ygm@mail.sysu.edu.cn

*Contributed equally

Key words: triptolide, cell cycle, apoptosis, renal cell carcinoma median survival of less than one year (2). Besides, for those with a single kidney, a non-functional contralateral kidney or bilateral RCC, it is also a problem to select an appropriate therapy strategy (3). For these people unsuitable for surgery, standard treatments such as traditional chemotherapy, radiotherapy and immunotherapy largely lack efficacy and are poorly tolerated (4). Therefore, efforts to develop a new drug targeting molecular pathways involved in tumor growth are urgently needed in order to improve the outcome of patients with advanced and refractory RCC.

A particularly potent driving force for the progression of carcinogenesis is the coupled relationship between deregulated cell cycle and inhibition of cell apoptosis, as cancer is a disease of deregulated cell proliferation and survival (5). Based on their critical role in all tumor development, therapeutic targeting of cell cycle and apoptosis are utilized as two obvious strategies to cancer intervention (6). Studies have shown that cells will either return to G0 phase or re-differentiate if arrested at G1 checkpoint, while the cells will die by apoptosis if arrested at any of the checkpoints except G1 checkpoint (7-9). In clinic, cell cycle specific cytotoxic agents which have been widely applied as the common drugs of the chemotherapy regimen for years, do rely on this theory and accumulate cancer cells in S or M phases followed by cell apoptosis, such as DNA synthesis inhibitors methotrexate and 5-fluoro-2,4 $(1 \mathrm{H}, 3 \mathrm{H})$ pyrimidinedione and tubulin-interactive drugs paclitaxel and colchicine (10-13). Although causing some side-effects, these chemotherapeutic agents specific to cancer cells in $\mathrm{S}$ or $\mathrm{M}$ phases have brought great benefits and a new outlook for cancer therapy.

Triptolide, the major active component of the Chinese medicinal herb Tripterygium wilfordii Hook F (TWHF), has been used as an effective agent to immunological nephritis and rheumatoid arthritis for years $(14,15)$. As a small molecule (MW: 360.6), triptolide (see Fig. 1 for the structure) at nanomolar concentrations presents not only anti-inflammatory and -immunity activities, but also strong in vivo and in vitro anti-neoplastic activity in a broad rage of cancer types not including renal cell carcinoma (16-18). Most studies revealed the pro-apoptotic effect of triptolide, however, the relationship between cell cycle and apoptosis has not been clarified. We analyze the effects of triptolide on apoptosis and cell cycle in human renal cell carcinoma cells and explore the possible mechanisms involved. 


\section{Materials and methods}

Culture and reagents. The human renal cell carcinoma cell lines 786-0 and OS-RC-2, were grown in RPMI-1640 medium supplemented with $10 \%$ fetal bovine serum (FBS) (Invitrogen, Grand Island, NY). Cells were cultured in a $5 \% \mathrm{CO}_{2}$-humidified atmosphere at $37^{\circ} \mathrm{C}$. Triptolide (Sigma-Aldrich, St. Louis, MO) was dissolved in dimethyl sulfoxide (DMSO) to obtain $1 \mathrm{mM}$ stock solution, and then was added in medium at indicated concentrations for indicated durations.

Cell viability assay. Cell viability assay was conducted as previously described (19). Briefly, cells after treatment were incubated with 3-(4, 5-dimethylthiazol-2-yl)-2, 5-diphenyl tetrazolium bromide (MTT) solution (Sigma, $5 \mathrm{mg} / \mathrm{ml}$ in PBS) to induce the production of formazan crystals and then $100 \mu 1$ DMSO was added to solubilize the formazan crystal. The optical density (OD) was determined at $570 \mathrm{~nm}$ using an iMark $^{\mathrm{TM}}$ Microplate Reader (Bio-Rad, Richmond, CA). The cell viability rate $=$ OD experiment/OD control $\times 100 \%$.

Hoechst 33258 staining. The method was carried out as previously described (19). In brief, cells were fixed with $4 \%$ paraform for $10 \mathrm{~min}$, stained with Hoechst 33258 (Sigma) at $5 \mu \mathrm{g} / \mathrm{ml}$ for $15 \mathrm{~min}$ in the dark, and observed by fluorescence microscopy with a $340 \mathrm{~nm}$ excitation filter.

Annexin V-fluorescein isothiocyanate (FITC)/propidium iodide (PI) assay. For determination of apoptosis and necrosis, cells treated with triptolide were analyzed by using a TACS ${ }^{\mathrm{TM}}$ Annexin V-FITC staining kit (R\&D Systems, Minneapolis, $\mathrm{MN}$ ) according to the manufacturer's recommendation.

Cell cycle analysis. After $24 \mathrm{~h}$ of serum starvation, cells were exposed to the complete medium with 10\% FBS and triptolide at different concentrations for various durations and then were harvested by trypsinization, washed in cool PBS twice and fixed in $75 \%$ ethanol overnight at $4^{\circ} \mathrm{C}$. Cells were then incubated in solution with $50 \mathrm{mg} / \mathrm{ml}$ DNA-binding dye PI, $4 \mathrm{Ku} / \mathrm{ml} \mathrm{RNase}, 0.3 \mathrm{mg} / \mathrm{ml} \mathrm{NaF}$ and $1 \mathrm{mg} / \mathrm{ml}$ sodium citrate for $30 \mathrm{~min}$ at $37^{\circ} \mathrm{C}$ away from light. Finally, red fluorescence from $488 \mathrm{~nm}$ laser-excited PI in cells was analyzed by EPICS ALTRA flow cytometer (Beckman Coulter, Fullerton, CA) using a peak fluorescence gate to discriminate aggregates. The percentage of cells in G0/G1, S and G2/M phases was determined from DNA content histograms by Multicycle for windows (Phoenix Flow Systems, San Diego, CA).

Release of cytochrome c. Cytochrome c concentration in cytoplasm was determined using Quantikine cytochrome c immunoassay kit (R\&D Systems) according to the manufacturer's instruction. The cytoplasmic protein was collected using nuclear and cytoplasmic extraction reagents (Pierce, Rockford, IL), normalized using BCA protein assay kit (Pierce) and stored at $-70^{\circ} \mathrm{C}$ until assay for cytochrome $\mathrm{c}$.

Measurement of caspase activity. Caspase 3 and 8 activities were assessed by caspase 3 and 8 colorimetric assay kit, respectively (Keygen, Nanjing, China). After different treatment for various times, $5 \times 10^{6}$ cells were collected and

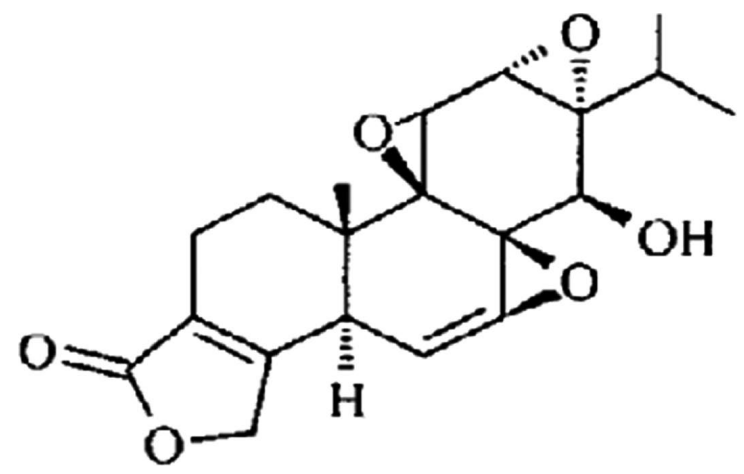

Figure 1. The chemical structure of triptolide.

resuspended in $50 \mu 1$ lysate. After spallation, lysis solution was normalized using BCA protein assay kit and then incubated with $50 \mu 1$ reaction buffer and $5 \mu 1$ substrate solution for $4 \mathrm{~h}$ at $37^{\circ} \mathrm{C}$ in the dark. The optical density (OD) was determined at $405 \mathrm{~nm}$ using an iMark Microplate Reader.

Western blot analysis. Western blot was carried out as previously described (19). The following antibodies were used: antibodies against $\beta$-actin (1:1000, Neomarker, CA, USA), GAPDH (1:2000, Cell Signaling Technology, Beverly, MA), Bax (1:1000, Cell Signaling Technology), Bcl-2 (1:1000, Cell Signaling Technology), Bcl- $\mathrm{X}_{\mathrm{L}}(1: 1000$, Cell Signaling Technology), Rb (1:500, Santa Cruz, CA, USA), phosphorylated-Rb (1:1000, Cell Signaling Technology), E2F1 (1:1000, Cell Signaling Technology), cyclin A (1:1000, Cell Signaling Technology), cyclin B (1:1000, Cell Signaling Technology), CDK1 (1:1000, Cell Signaling Technology) and CDK2 (1:1000, Cell Signaling Technology).

Statistical analysis. Data are presented as the mean \pm standard deviation (SD) of three separate experiments. Statistical significance was determined by ANOVA analysis. Values with $\mathrm{p}<0.05$ were considered to be statistically significant.

\section{Results}

Triptolide dose-dependently decreases cell viability and induces cell apoptosis in human renal carcinoma cell line 786-0 cells. To investigate the effects of triptolide on growth and survival of renal cell carcinoma cells, we treated human renal cell carcinoma 786-0 cells with increasing concentrations of triptolide from 12.5 to $200 \mathrm{nM}$ for 24 and $48 \mathrm{~h}$. As shown in Fig. 2A, triptolide in nanomolar concentrations induced significant cell viability loss. At $50 \mathrm{nM}$, the inhibitory effect of triptolide seemed to reach the maximum extent and the cell viability reduced to $35.3 \%$ of control. Besides, triptolideinduced cell viability loss presented a time-dependent trend.

Furthermore, we tested cell apoptosis by Hoechst staining and Annexin V-PI double staining. When 786-0 cells were exposed to $12.5,25$ and $50 \mathrm{nM}$ triptolide for $48 \mathrm{~h}$, apoptotic cells characterized by morphological alteration such as condensed nuclei and cell shrinkage were observed and the apoptotic cell number increased with the dose (Fig. 2B). Phosphatidylserine externalization is a parameter of apoptosis, which can be 
A

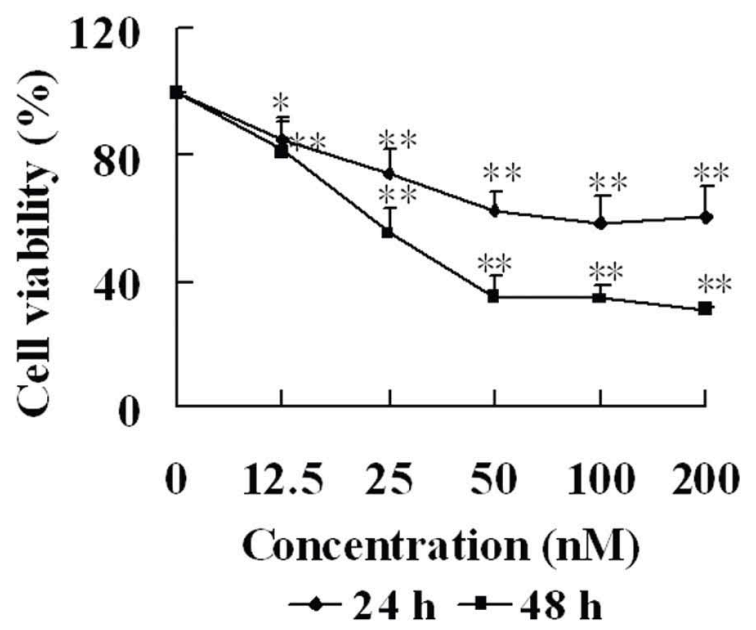

B
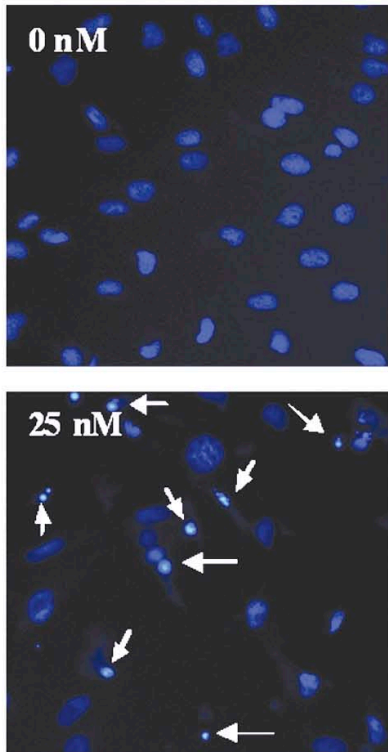
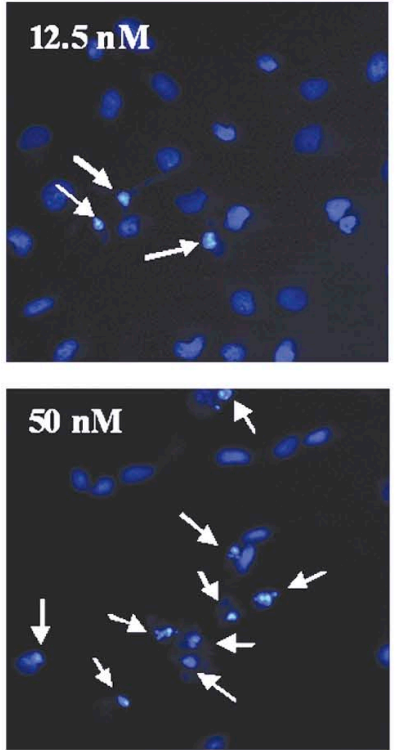

C

o nM
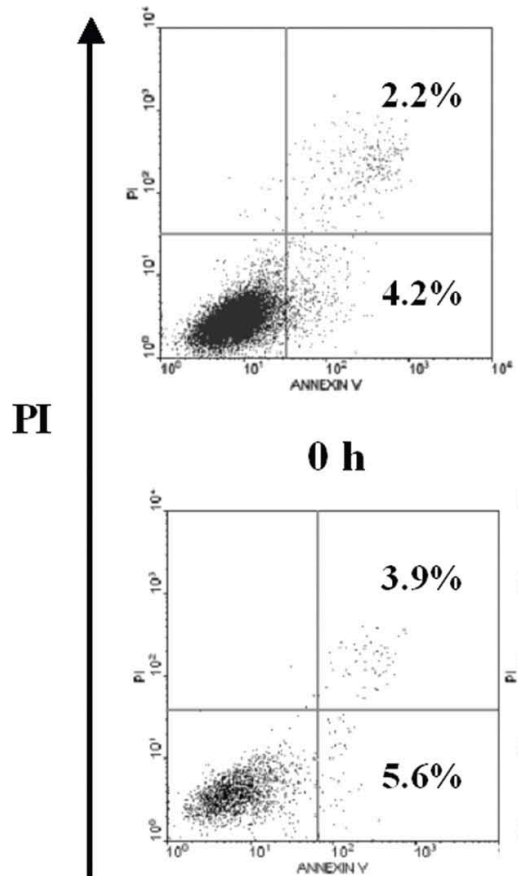

$12.5 \mathrm{nM}$

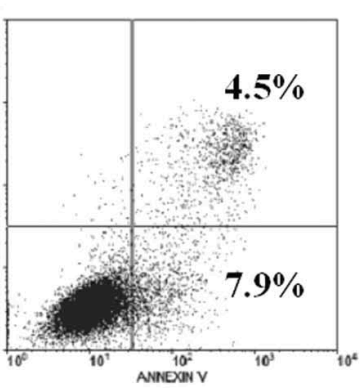

$12 \mathrm{~h}$

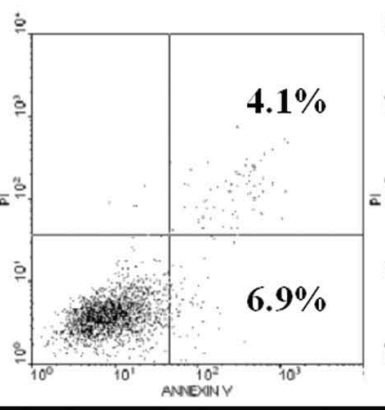

$25 \mathrm{nM}$

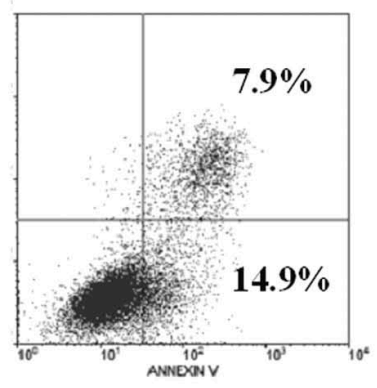

$24 \mathrm{~h}$

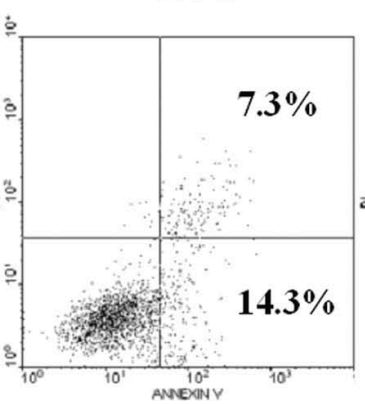

$50 \mathrm{nM}$

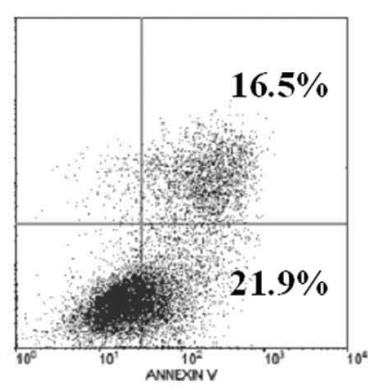

48 h

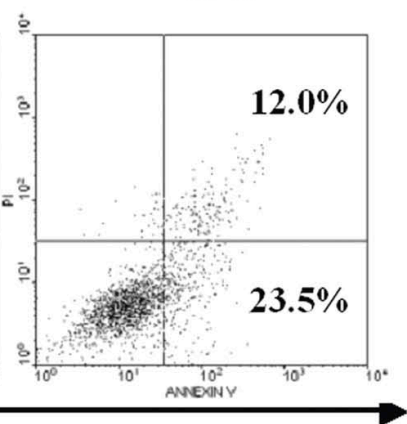

\section{Annexin V}

Figure 2. Triptolide dose-dependently decreased the cell viability and induced cell apoptosis in human renal carcinoma cell line $786-0$ cells. (A) The effect of triptolide on the cell viability. The data are the mean \pm SD $(n=3) .{ }^{*} \mathrm{p}<0.05,{ }^{* *} \mathrm{p}<0.01$ compared with the control. (B) Hoechst 33258 staining. $786-0$ cells were incubated with 12.5, 25 and $50 \mathrm{nM}$ triptolide for $48 \mathrm{~h}$. (C) Annexin V-PI staining. 786-0 cells were incubated with $12.5,25$ and $50 \mathrm{nM}$ triptolide for $48 \mathrm{~h}$ or with $50 \mathrm{nM}$ for 12, 24 and $48 \mathrm{~h}$. Percentages of early apoptotic (positive Annexin V staining) and necrotic/late apoptotic (stained positive for both Annexin V-FITC and PI) are shown.

measured by Annexin V-PI double staining. Annexin V-FITC binds to exposed phosphatidylserine on apoptotic and necrotic cells, and PI gains entry into the late apoptotic cells and necrotic cells. Cells located in the lower right quadrant that were Annexin V alone-positive belong to the early apoptotic stage, and ones in the upper right quadrant that were Annexin $\mathrm{V}$ and PI double-positive belong to the late apoptotic or necrotic cells. After $48 \mathrm{~h}$, triptolide dose-dependently increased 
A

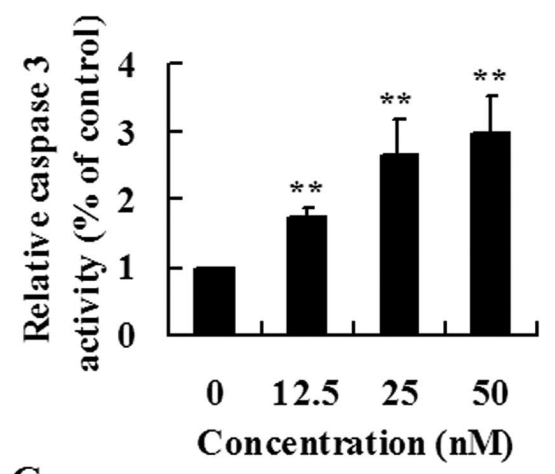

C

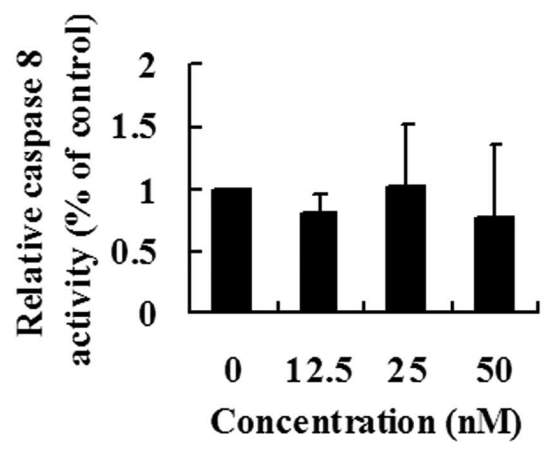

B
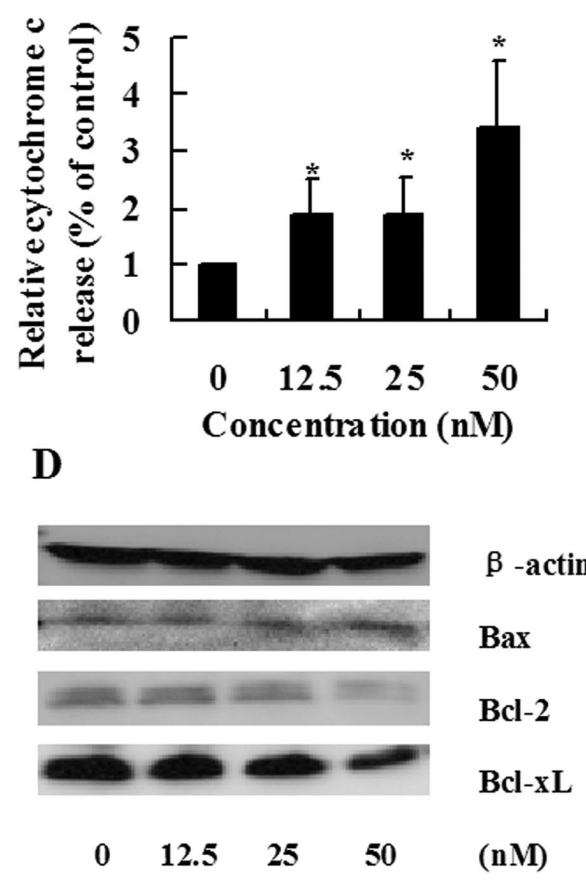

Figure 3. Triptolide-triggered apoptosis is mediated via the mitochondrial pathway in 786-0 cells. (A-C) The effect of triptolide on caspase 3 (A), 8 (C) activity and cytochrome $\mathrm{c}$ release (B). 786-0 cells were incubated with 12.5, 25 and $50 \mathrm{nM}$ triptolide for $48 \mathrm{~h}$. The data are the mean $\pm \mathrm{SD}(\mathrm{n}=3) .{ }^{*} \mathrm{p}<0.05,{ }^{* * *} \mathrm{p}<0.01 \mathrm{com}-$ pared with the control. (D) Effects of triptolide on the protein levels of Bax, Bcl-2 and Bcl- $\mathrm{X}_{\mathrm{L}}$. Cells were treated with $12.5,25$ and $50 \mathrm{nM}$ triptolide for $48 \mathrm{~h}$.

Annexin $\mathrm{V}$ alone and Annexin V PI double-positive cells in 786-0 cells (Fig. 2C). After exposure to $50 \mathrm{nM}$ triptolide for 12 , 24 and $48 \mathrm{~h}$, the number of Annexin V alone and Annexin V PI double-positive cells significantly increased with the time. This result confirms that cell viability loss induced by triptolide in 786- 0 cells is facilitated by the induction of apoptosis.

Triptolide-triggered apoptosis is mediated via the mitochondrial pathway in 786-0 cells. Cell apoptosis can be triggered by intrinsic/mitochondrial pathway or extrinsic/the death receptor signaling pathway. To assess the pathway by which triptolide induces cell apoptosis, several markers of apoptosis were analyzed, including the activity of caspase- 3 which is activated through whatever the intrinsic or extrinsic pathway, the activity of caspase- 8 which is activated through the death receptor signaling pathway, and the release of cytochrome c which is secreted from the mitochondria into the cytosol when the intrinsic pathway is initiated (20-23). Significantly, caspase- 3 activity and cytochrome c release were enhanced to approximately 3 -fold at $50 \mathrm{nM}$ triptolide, while caspase- 8 activity did not alter at tested concentrations. These data provide a possibility that triptolide-induced apoptosis is mediated by mitochondrial pathway.

The Bcl-2 family of proteins stands among the most crucial regulators of apoptosis and influences the stability of the mitochondrial membrane after intrinsic or extrinsic stimulators (24). The ratio of pro-apoptotic proteins such as Bax and anti-apoptotic ones such as $\mathrm{Bcl}-2, \mathrm{Bcl}_{-} \mathrm{X}_{\mathrm{L}}$ performs a vital function in deciding whether a cell is killed or survive (25).
In response to triptolide at $12.5,25$ and $50 \mathrm{nM}$, the protein level of Bax slightly climbed, while those of Bcl-2 and Bcl- $\mathrm{X}_{\mathrm{L}}$ declined. Bax/Bcl-2, Bcl- $\mathrm{X}_{\mathrm{L}}$ increase would result in the disruption of the mitochondria and the release of cytochrome $\mathrm{c}$, then provoke caspase-3 activation and eventually trigger cell apoptosis (Fig. 3).

Triptolide initiates cell cycle arrest at $S$ phase via influencing cell cycle-related factors in 786-0 cells. To explore whether triptolide-induced apoptosis is related to the alteration of cell cycle, we respectively detected the dose- and time-dependent effect of triptolide on cell cycle distribution. When 786-0 cells were incubated with $0,12.5,25$ and $50 \mathrm{nM}$ triptolide, the cell population of G0/G1 phase gradually decreased from 65.3 to $34.5 \%$, one of $\mathrm{S}$ phase rised from 27.7 to $63.9 \%$ with dose, and one of G2/M phase dropped from 7.1 to $1.6 \%$ by degrees. Similarly, the same trend was observed after triptolide treatment for 12, 24 and $48 \mathrm{~h}$. Especially at $48 \mathrm{~h}$ post-incubation with $50 \mathrm{nM}$ triptolide, more than half of tumor cells showed the $2 \mathrm{~N}-4 \mathrm{~N}$ karyotype, indicating a cell cycle arrest at $\mathrm{S}$ phase (Fig. 4A).

To probe the mechanism by which triptolide initiated such a cell cycle arrest, the following investigation was focused on the cell cycle checkpoint-cyclins, cyclin-dependent kinases (CDK) and other cell cycle-related factors. Firstly, we measured the $\mathrm{G} 1$ to $\mathrm{S}$ phase checkpoint-retinoblastoma protein $(\mathrm{Rb})$, which binds to transcription factor E2F1 in the resting state and in the phosphorylated state releases the activated E2F1 that subsequently promotes gene transcription required for $\mathrm{S}$ phase entry $(26,27)$. After $12.5-50 \mathrm{nM}$ triptolide treatment 
A
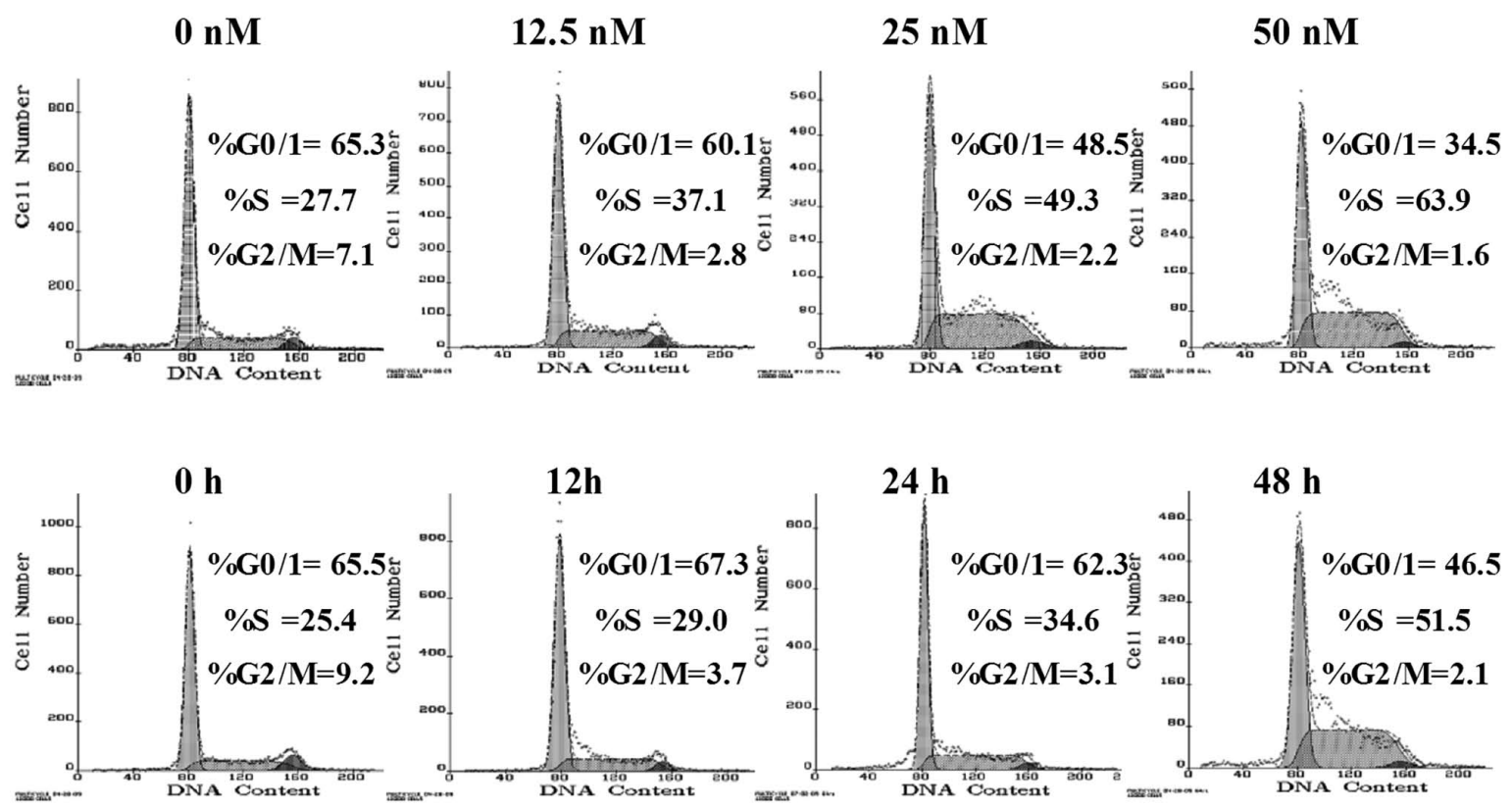

B

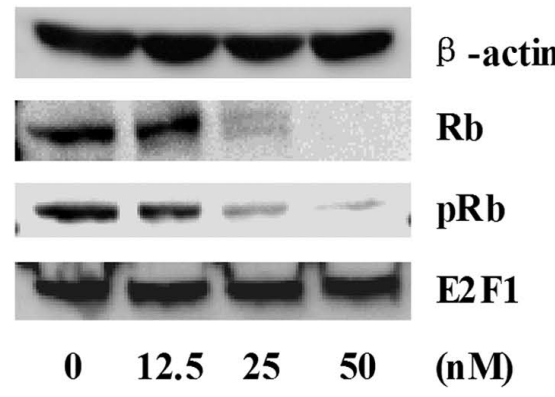

C

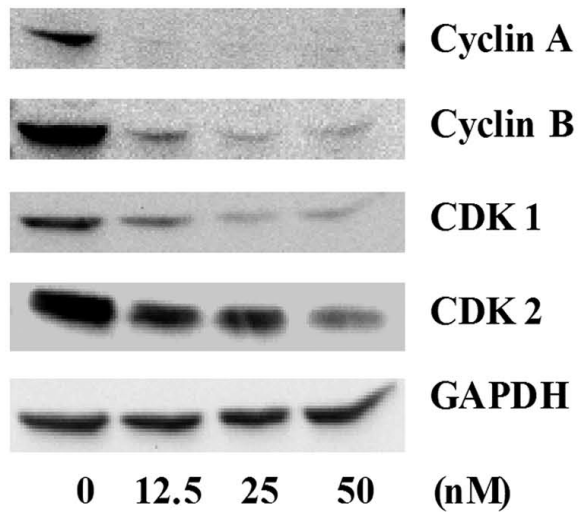

Figure 4. Triptolide initiated cell cycle arrest at S phase via influencing cell cycle related factors in 786-0 cells. (A) The dose- and time-dependent effect of triptolide on cell cycle distribution. 786-0 cells were incubated with 12.5, 25 and $50 \mathrm{nM}$ triptolide for $48 \mathrm{~h}$ or with $50 \mathrm{nM}$ for 12,24 and $48 \mathrm{~h}$. Percentages of cells at G0/G1, S and G2/M phases are shown. (B and C) Effects of triptolide on the protein levels of Rb, pRb, E2F1 (B) and cyclin A, cyclin B, CDK1, CDK2 (C). Cells were treated with $12.5,25$ and $50 \mathrm{nM}$ triptolide for $48 \mathrm{~h}$.

for $48 \mathrm{~h}$, the total $\mathrm{Rb}$ gradually declined to a nearly undetectable level, concurrent with the reduced phosphorylated $\mathrm{Rb}$ $(\mathrm{pRb})$. In a parallel assay, we did not detect any alteration in the total E2F1 protein, indicating that the reduction of $\mathrm{Rb}$ may contribute to the increasing release of free E2F1 and then trigger cells to enter into $S$ phase more rapidly (Fig. 4B). Secondly, cyclin A/CDK1 or CDK2 complexes, responsible for the check of DNA duplication in $\mathrm{S}$ phase and entering into $\mathrm{G} 2$ phase from $\mathrm{S}$ phase, were also reduced to an extreme low level (28). Furthermore, the diminution of cyclin B/CDK1 complex called the mitosis promoting factor (MPF) implied the hindrance of the G2 to M transition (29) (Fig. 4C). Taken together, we can deduce that triptolide kept cells accumulating in S phase via possibly impelling more cells passing the G1 to $\mathrm{S}$ checkpoint and at the same time stopping the export from $\mathrm{S}$ phase (Fig. 6).
Triptolide induces cell viability loss, cell apoptosis and $S$ phase cell cycle arrest in the human renal cell carcinoma $O S-R C$-2 cells. To clarify whether triptolide-induced apoptosis and cell cycle arrest is cell-specific, we used the human renal cell carcinoma cell line OS-RC-2. As shown in Fig. 5A, triptolide also reduced the cell viability of OS-RC-2 cells dose- and time-dependently, and similar to 786-0 cells, the cell viability did not continue to decline when the dose reached $50 \mathrm{nM}$. Then triptolide-induced dose-dependent apoptosis of OS-RC-2 cells has been confirmed by Hoechst staining and caspase- 3 activity assay (Fig. 5B and C). In addition, a concentration-dependent increase in cell proportion at $\mathrm{S}$ phase (from 12.2 to $26.6 \%$ ) further supported the notion that triptolide has no cell line-specific effect to induce apoptosis and cell cycle arrest at $S$ phase in human renal cell carcinoma (Fig. 5D). 
A

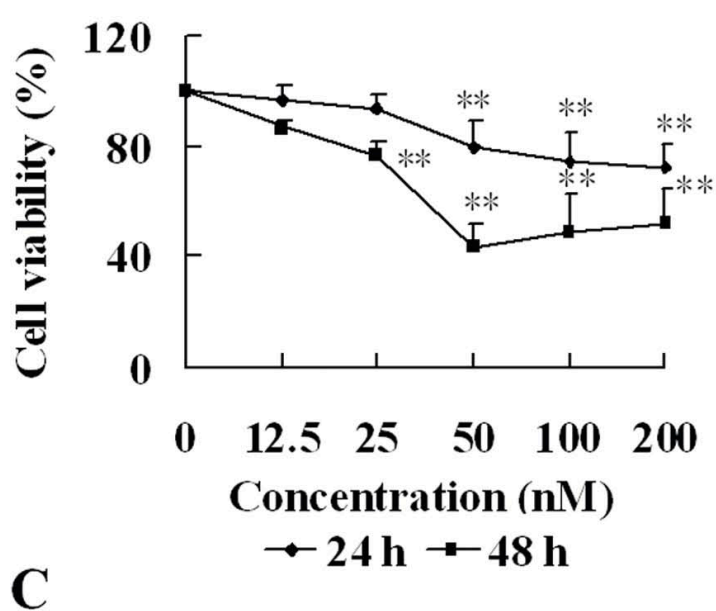

B

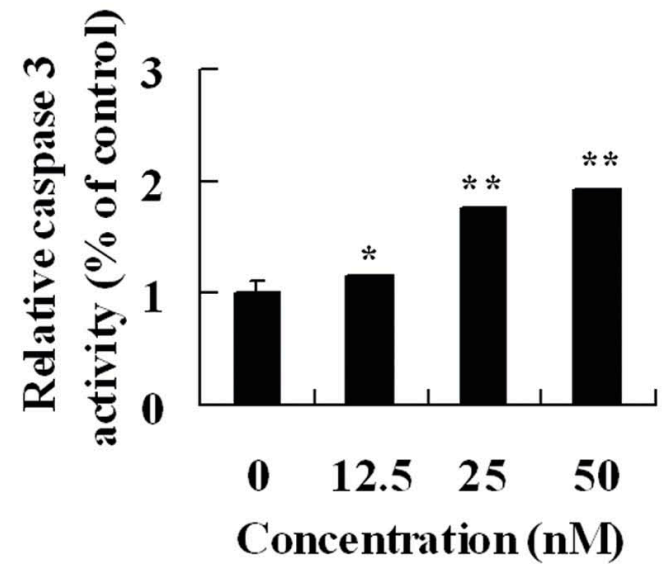

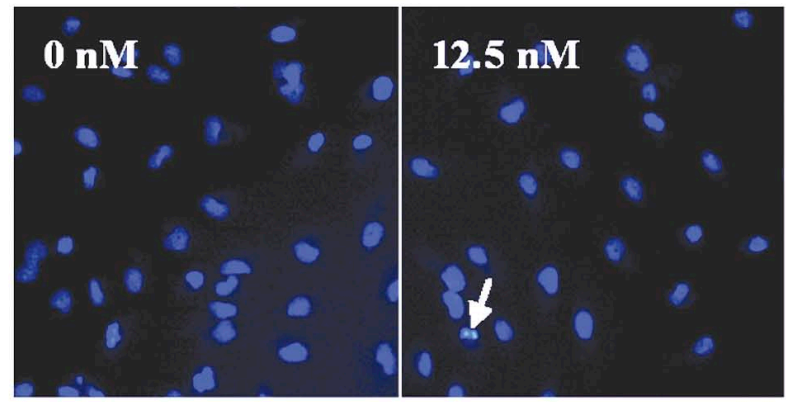

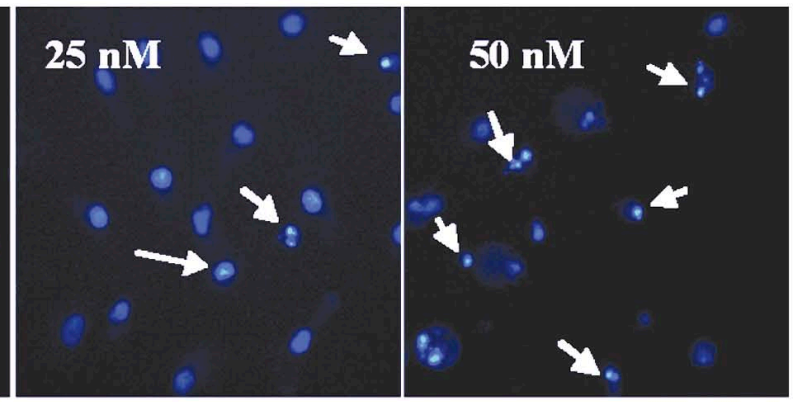

D

$0 \mathrm{nM}$

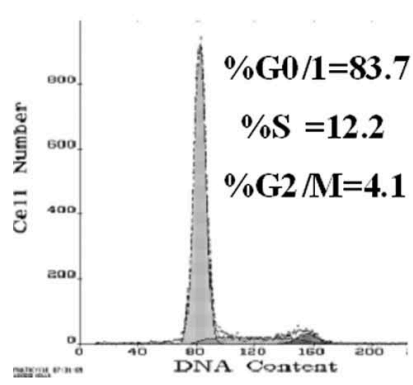

$12.5 \mathrm{nM}$

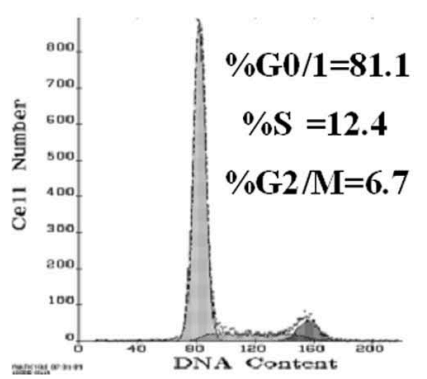

$25 \mathrm{nM}$

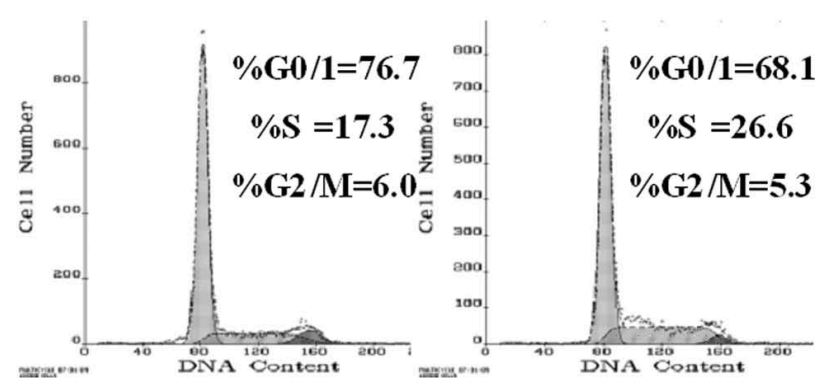

Figure 5. Triptolide induces cell viability loss, cell apoptosis and S phase cell cycle arrest in the human renal cell carcinoma OS-RC-2 cells. (A) The effect of triptolide on the cell viability. (B) The effect of triptolide on caspase 3 activity. The data are the mean \pm SD $(n=3)$. ${ }^{*}<<0.05$, ${ }^{* *} p<0.01$ compared with the control (A and B). (C) Hoechst 33258 staining. (D) The effect of triptolide on cell cycle distribution. OS-RC-2 cells were incubated with 12.5 , 25 and 50 nM triptolide for $48 \mathrm{~h}(\mathrm{~B}, \mathrm{C}$ and $\mathrm{D})$.

\section{Discussion}

RCC, also called renal adenocarcinoma, accounts for $>90 \%$ of malignancy arising from the kidney. Although the proportion of RCC in all adult malignant tumors is only $2 \%$, the incidence is continuously increasing (30). Radical nephrectomy is the only curative and effective treatment option for located RCC. However, this operation greatly reduces the life quality of patients diagnosed with RCC, and cannot be applied to those with a single kidney or functionally compromised contralateral kidney and those with bilateral RCC or advanced RCC. Meanwhile, for those special RCC mentioned above, the high existence of multidrug-resistant gene in RCC causes the resistance of $\mathrm{RCC}$ to common cytotoxic chemotherapy drugs
(31). Up to now, despite the application of surgery, combined with chemotherapy and systemic therapy, the outcome of these refractory RCC have been proved disappointing. In our study, the small molecule triptolide that has been confirmed to be cytotoxic to almost all tested cancer cells even though those transfected with multidrug-resistant gene (17), also showed a significant pro-apoptotic effect in human renal cell carcinoma cells. Cell apoptosis seems like to be closely associated with the cell cycle arrest in $\mathrm{S}$ phase via accelerating cells into $\mathrm{S}$ phase and hampering cells out from $\mathrm{S}$ phase.

The cell cycle is controlled by a series of key components including cyclins, cyclin-dependent kinases and some regulatory factors. In every cell cycle transition, there always exists different complex as the checkpoint which thus becomes the 


\section{Cell cycle}

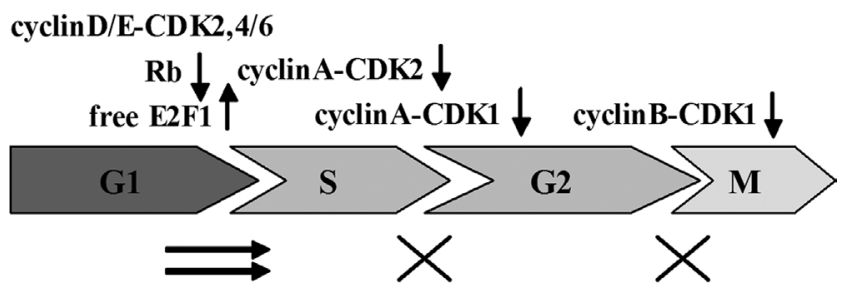

Cell accumulation at $S$ phase

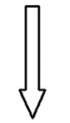

\section{Activation of the cell-intrinsic apoptotic pathway \\ Release of cytochrome c \\ Activation of caspase 9 and 3 \\ DNA fragme ntation}

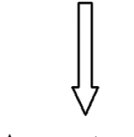

\section{Apoptosis}

Figure 6. The schematic graph that demonstrates the effects and mechanism of triptolide on cell cycle and apoptosis in human renal cell carcinoma cells.

potential target of deregulated cell cycle-associated diseases, especially cancer. In transition of G1 to S, cyclin D/CDK4 or 6 and cyclin E/CDK2 complexes form, phosphorylate $\mathrm{Rb}$ and release free E2F, thereby subsequently activating gene transcription required for $\mathrm{S}$ phase entry $(26,32,33)$. Following the preparation of DNA synthesis-associated proteins, cyclin $\mathrm{A} / \mathrm{CDK} 2$ complex is required for the check of DNA synthesis (28). Later in S phase, cyclin A alters to bind to CDK1 (also termed CDC2), and allows cells to enter into G2 phase $(28,34)$. In the late $\mathrm{G} 2$ phase, CDK1 detaches from cyclinA and associates with cyclin B. The new complex is also termed MPF and is necessary for the cell mitosis $(28,29,35,36)$. We found triptolide-reduced $\mathrm{Rb}$ protein but had no effect on $\mathrm{E} 2 \mathrm{~F} 1$ protein. So we speculate that triptolide elevated the free E2F1 level and thus promoted more cells into $\mathrm{S}$ phase. In addition, every component of cyclin A/CDK1,2 complexes was down-regulated, indicating that the DNA synthesis and the transition of $\mathrm{S}$ to $\mathrm{G} 2$ phase is most possibly influenced, and then cells remain in $\mathrm{S}$ phase. Besides, the reduction of MPF would inevitably stop the cell mitosis. Triptolide-induced cell cycle arrest at $\mathrm{S}$ phase is mediated via regulating cell cycle-associated factors. This phenomenon occurred not just in renal cell carcinoma but in acute myeloid leukemia (AML), breast intraductal carcinoma, and fibrosarcoma (16,37-39). Moreover, the inhibitory activity of triptolide to expression of cell regulatory molecules also agrees with the Western blotting data reported on human breast carcinoma cells that showed triptolide treatments caused a reduction in the levels of pRb, cyclin A, cyclin B1, cyclin D1, c-myc, CDK2 and CDC2 (17). Nevertheless, some researches demonstrated that triptolide treatment triggered a G0/G1 cell cycle arrest and apoptosis in gastric cancer and multiple myeloma cells $(40,41)$.
Taken together, these results indicate that the cell cycle phase arrest triptolide will induce is cancer cell type-specific, but any cell cycle arrest eventually results in cell apoptosis.

The main pathway executing the cell death program includes the extrinsic one which involves the binding of ligand to the death receptor and subsequent caspase 8 activation, and the intrinsic one (the mitochondria-dependent pathway) which relies on the release of apoptosis-inducing factor from mitochondria to the cytosol, such as cytochrome c that evokes caspase cascade and finally activates caspase 3 (20-23). The key components of the machinery that drive cells through the mitochondria-dependent apoptosis are $\mathrm{Bcl}-2$ family of proteins, including pro-apoptotic Bax and anti-apoptotic Bcl-2, $-\mathrm{X}_{\mathrm{L}}$ proteins (25). Bax acts as a destroyer of the mitochondrial membrane and facilitates the cytochrome c release. Bcl-2 and $\mathrm{Bcl}-\mathrm{X}_{\mathrm{L}}$ usually bind to Bax and form heterodimer, thus hindering the Bax-triggered cell death program. In this study, triptolide increased the activation of caspase 3 and the release of cytochrome $\mathrm{c}$ into the cytosol, but not caspase 8 activation. These data provide strong evidence for the conclusion that triptolide-induced apoptosis in renal cell carcinoma cells is mediated via the the mitochondria-dependent pathway. Moreover, the elevated Bax expression and the lessened Bcl-2 and $\mathrm{Bcl}-\mathrm{X}_{\mathrm{L}}$ expression further disclose that the initiation of the intrinsic pathway owes to the up-regulation of the Bax/ Bcl-2, $-\mathrm{X}_{\mathrm{L}}$ ratio. According to previous reports on triptolide's pro-apoptotic activity, in majority of cells, triptolide-induced cytotoxity is through the mitochondrial pathway $(37,42-47)$. With regard to the mechanism how triptolide triggers the mitochondria-dependent pathway, some researchers consider that it attributes to the increasing level of Bax protein and the decreasing level of Bcl-2, $-\mathrm{X}_{\mathrm{L}}(38,47,48)$, which concord with our conclusion. The downregulation of X-linked inhibitor of apoptosis protein (XIAP) in AML cells has also been reported (43). In spite of the change or not in Bcl-2 protein level, overexpression of Bcl-2 can greatly attenuate triptolideinduced apoptosis, suggesting the critical role of Bcl-2 in the triptolide-triggered apoptosis $(37,43,46)$.

It is well-known that if cells are blocked in any phase of the cell cycle except the G0/G1 phase, they will be destined to experience the cell death program. In human renal cell carcinoma, we confirmed that triptolide accumulated cells in $\mathrm{S}$ phase and thus caused cell apoptosis. Apoptosis and cell cycle affect both processes by cell cycle regulators and apoptotic stimuli (49). Although toxicants may initiate cell damage or stress, cellular proteins regulate the toxic stress response by a physiological balance between cell proliferation and death. In our work, triptolide increased free E2F1 levels that is mainly involved in cell cycle regulation and down-regulated the anti-apoptotic proteins of Bcl-2 family. E2F1, as an important transcription factor, can directly regulate not only genes required for the $\mathrm{G} 1$ to $\mathrm{S}$ phase transition, but also genes controlling apoptosis $(50,51)$. The recent study on the regulatory relation between $\mathrm{Bcl}-2$ and $\mathrm{E} 2 \mathrm{~F} 1, \mathrm{c}-\mathrm{myc}$ demonstrated that E2F1 and c-myc DNA binding activity is required to suppress Bcl-2 expression (52). It has also been shown that overexpression of E2F1 can induce cell apoptosis in several cancer cell types and the E2F1-induced apoptosis is related to the downregulation of Bcl-2 family member proteins (53). In triptolide-induced apoptosis, we argue that the increased 
release of E2F1 may contribute to the downregulation of $\mathrm{Bcl}-2$ and $\mathrm{Bcl}-\mathrm{X}_{\mathrm{L}}$ expression.

In conclusion, we showed that the small molecule triptolide induced increased $\mathrm{Bax} / \mathrm{Bcl}-2,-\mathrm{X}_{\mathrm{L}}$ ratio, cytochrome c release, caspase 3 activation and the final mitochondriadependent apoptosis in human renal cell carcinoma (Fig. 6), downregulated the expressions of $\mathrm{Rb}$, cyclin A, cyclin B, $\mathrm{CDK} 1$ and $\mathrm{CDK} 2$ and triggered cell cycle arrest at $\mathrm{S}$ phase (Fig. 6). Although the exact mechanism and efficacy of triptolide-induced apoptosis in vivo is waiting further investigation, triptolide-induced apoptosis and cell cycle arrest in human renal carcinoma cells may also constitute an important mechanism for triptolide-induced anti-tumor activity, and triptolide could potentially be developed to a new chemotherapy agent to treat renal cell carcinoma.

\section{Acknowledgements}

This work was supported by Key program, National Natural Science Foundation of China (no. 30830111), National Natural Science Foundation of China (no. 330801408), National Natural Science Foundation of Guangdong Province (no. 8451008901000297) and China Postdoctoral Science Foundation funded project (Grant no. 20100480824).

\section{References}

1. Wood LS: Renal cell carcinoma: Screening, diagnosis, and prognosis. Clin J Oncol Nurs 13 (Suppl.): S3-S7, 2009.

2. Ather MH, Masood N and Siddiqui T: Current management of advanced and metastatic renal cell carcinoma. Urol J 7: 1-9, 2010.

3. Zigeuner $\mathrm{R}$ and Pummer $\mathrm{K}$ : [Current surgical aspects of renal cell carcinoma]. Wien Med Wochenschr 159: 535-542, 2009.

4. Basso M, Cassano A and Barone C: A survey of therapy for advanced renal cell carcinoma. Urol Oncol 28: 121-133, 2010.

5. Evan GI and Vousden KH: Proliferation, cell cycle and apoptosis in cancer. Nature 411: 342-348, 2001.

6. Senderowicz AM: Targeting cell cycle and apoptosis for the treatment of human malignancies. Curr Opin Cell Biol 16: 670-678, 2004.

7. Liu DX and Greene LA: Neuronal apoptosis at the g1/s cell cycle checkpoint. Cell Tissue Res 305: 217-228, 2001.

8. Philipson L: Cell cycle exit: Growth arrest, apoptosis, and tumor suppression revisited. Mol Med 4: 205-213, 1998.

9. Pietenpol JA and Stewart ZA: Cell cycle checkpoint signaling: Cell cycle arrest versus apoptosis. Toxicology 181-182: 475-481, 2002.

10. Dittmann H, Dohmen BM, Kehlbach R, et al: Early changes in [18f]flt uptake after chemotherapy: An experimental study. Eur J Nucl Med Mol Imaging 29: 1462-1469, 2002.

11. McCormack ES, Borzillo GV, Ambrosino C, et al: Transforming growth factor-beta3 protection of epithelial cells from cycle-selective chemotherapy in vitro. Biochem Pharmacol 53: 1149-1159, 1997.

12. Long HJ: Paclitaxel (taxol): A novel anticancer chemotherapeutic drug. Mayo Clin Proc 69: 341-345, 1994.

13. Wang JL, Gunther GR and Edelman GM: Inhibition by colchicine of the mitogenic stimulation of lymphocytes prior to the $\mathrm{S}$ phase. J Cell Biol 66: 128-144, 1975.

14. Chen BJ: Triptolide, a novel immunosuppressive and antiinflammatory agent purified from a Chinese herb tripterygium wilfordii hook f. Leuk Lymphoma 42: 253-265, 2001.

15. Gu WZ, Chen R, Brandwein S, McAlpine J and Burres N: Isolation, purification, and characterization of immunosuppressive compounds from tripterygium: Triptolide and tripdiolide. Int J Immunopharmacol 17: 351-356, 1995.

16. Chang WT, Kang JJ, Lee KY, et al: Triptolide and chemotherapy cooperate in tumor cell apoptosis. A role for the p53 pathway. J Biol Chem 276: 2221-2227, 2001.

17. Yang S, Chen J, Guo Z, et al: Triptolide inhibits the growth and metastasis of solid tumors. Mol Cancer Ther 2: 65-72, 2003.
18. Fidler JM, Li K, Chung C, et al: Pg490-88, a derivative of triptolide, causes tumor regression and sensitizes tumors to chemotherapy. Mol Cancer Ther 2: 855-862, 2003.

19. Zhu W, Ou Y, Li Y, et al: A small-molecule triptolide suppresses angiogenesis and invasion of human anaplastic thyroid carcinoma cells via down-regulation of the nuclear factor-kappa B pathway. Mol Pharmacol 75: 812-819, 2009.

20. Green DR: Apoptotic pathways: Paper wraps stone blunts scissors. Cell 102: 1-4, 2000.

21. Nagata S: Apoptosis by death factor. Cell 88: 355-365, 1997.

22. Kroemer G and Reed JC: Mitochondrial control of cell death. Nat Med 6: 513-519, 2000.

23. Reed JC: Apoptosis-regulating proteins as targets for drug discovery. Trends Mol Med 7: 314-319, 2001.

24. Kuwana T and Newmeyer DD: Bcl-2-family proteins and the role of mitochondria in apoptosis. Curr Opin Cell Biol 15: 691-699, 2003.

25. Gross A, McDonnell JM and Korsmeyer SJ: Bcl-2 family members and the mitochondria in apoptosis. Genes Dev 13: 1899-1911, 1999.

26. Sherr CJ: G1 phase progression: Cycling on cue. Cell 79: 551-555, 1994.

27. Sherr CJ: The ins and outs of Rb: Coupling gene expression to the cell cycle clock. Trends Cell Biol 4: 15-18, 1994.

28. Grana X and Reddy EP: Cell cycle control in mammalian cells: Role of cyclins, cyclin dependent kinases (cdks), growth suppressor genes and cyclin-dependent kinase inhibitors (ckis). Oncogene 11: 211-219, 1995.

29. Kobayashi H: [Mitotic cyclins and mpf]. Tanpakushitsu Kakusan Koso 38: 2293-2301, 1993.

30. Garcia JA, Cowey CL and Godley PA: Renal cell carcinoma. Curr Opin Oncol 21: 266-271, 2009.

31. Bolton DM, Wong P and Lawrentschuk N: Renal cell carcinoma: Imaging and therapy. Curr Opin Urol 17: 337-340, 2007.

32. Sherr CJ: Growth factor-regulated g1 cyclins. Stem Cells 12 (Suppl 1): 47-55, 1994.

33. Sherr CJ, Kato J, Quelle DE, Matsuoka M and Roussel MF: D-type cyclins and their cyclin-dependent kinases: G1 phase integrators of the mitogenic response. Cold Spring Harb Symp Quant Biol 59: 11-19, 1994.

34. Shakoori AR, van Wijnen AJ, Cooper C, et al: Cytokine induction of proliferation and expression of cdc2 and cyclin a in fdc-p1 myeloid hematopoietic progenitor cells: Regulation of ubiquitous and cell cycle-dependent histone gene transcription factors. J Cell Biochem 59: 291-302, 1995.

35. Maller JL: Mpf and cell cycle control. Adv Second Messenger Phosphoprotein Res 24: 323-328, 1990.

36. Masui Y: [Regulations of cell division cycles and $\mathrm{mpf}$ ]. Tanpakushitsu Kakusan Koso 38: 2285-2291, 1993.

37. Wan CK, Wang C, Cheung HY, Yang M and Fong WF: Triptolide induces bcl-2 cleavage and mitochondria dependent apoptosis in p53-deficient hl-60 cells. Cancer Lett 241: 31-41, 2006.

38. Kiviharju TM, Lecane PS, Sellers RG and Peehl DM: Antiproliferative and proapoptotic activities of triptolide (PG490), a natural product entering clinical trials, on primary cultures of human prostatic epithelial cells. Clin Cancer Res 8: 2666-2674, 2002.

39. Liu J, Jiang Z, Xiao J, et al: Effects of triptolide from tripterygium wilfordii on ERalpha and p53 expression in two human breast cancer cell lines. Phytomedicine 16: 1006-1013, 2009.

40. Jiang XH, Wong BC, Lin MC, et al: Functional p53 is required for triptolide-induced apoptosis and AP-1 and nuclear factor-kappaB activation in gastric cancer cells. Oncogene 20: 8009-8018, 2001.

41. Zhao F, Chen Y, Li R, Liu Y, Wen L and Zhang C: Triptolide alters histone $\mathrm{H} 3 \mathrm{~K} 9$ and $\mathrm{H} 3 \mathrm{~K} 27$ methylation state, and induces G0/G1 arrest and caspase-dependent apoptosis, in multiple myeloma in vitro. Toxicology 267: 70-79, 2009.

42. Su Y, Yang S, Xiao Z, Wang W, Okunieff P and Zhang L: Triptolide alters mitochondrial functions. Adv Exp Med Biol 599: 139-146, 2007.

43. Carter BZ, Mak DH, Schober WD, et al: Triptolide induces caspase-dependent cell death mediated via the mitochondrial pathway in leukemic cells. Blood 108: 630-637, 2006.

44. Jin Y, Chen Q, Shi X, et al: Activity of triptolide against human mast cells harboring the kinase domain mutant kit. Cancer Sci 100: 1335-1343, 2009.

45. Shi X, Jin Y, Cheng C, et al: Triptolide inhibits ber-abl transcription and induces apoptosis in sti571-resistant chronic myelogenous leukemia cells harboring $\mathrm{t} 315 \mathrm{i}$ mutation. Clin Cancer Res 15: 1686-1697, 2009. 
46. Wang X, Matta R, Shen G, Nelin LD, Pei D and Liu Y: Mechanism of triptolide-induced apoptosis: Effect on caspase activation and bid cleavage and essentiality of the hydroxyl group of triptolide. J Mol Med 84: 405-415, 2006.

47. Yao J, Jiang Z, Duan W, et al: Involvement of mitochondrial pathway in triptolide-induced cytotoxicity in human normal liver 1-02 cells. Biol Pharm Bull 31: 592-597, 2008.

48. Lin J, Chen LY, Lin ZX and Zhao ML: The effect of triptolide on apoptosis of glioblastoma multiforme (GBM) cells. J Int Med Res 35: 637-643, 2007.

49. Chiarugi V, Magnelli L and Cinelli M: Complex interplay among apoptosis factors: Rb, p53, E2F, TGF-beta, cell cycle inhibitors and the bcl2 gene family. Pharmacol Res 35: 257-261, 1997.
50. Harbour JW and Dean DC: Rb function in cell-cycle regulation and apoptosis. Nat Cell Biol 2: E65-E67, 2000.

51. DeGregori J and Johnson DG: Distinct and overlapping roles for E2F family members in transcription, proliferation and apoptosis. Curr Mol Med 6: 739-748, 2006.

52. Eischen CM, Packham G, Nip J, et al: Bcl-2 is an apoptotic target suppressed by both c-myc and e2f-1. Oncogene 20: 6983-6993, 2001.

53. Yang HL, Dong YB, Elliott MJ, Liu TJ and McMasters KM: Caspase activation and changes in bcl-2 family member protein expression associated with E2F-1-mediated apoptosis in human esophageal cancer cells. Clin Cancer Res 6: 1579-1589, 2000. 